\title{
An Achievement Motivation and Academic Anxiety of School Going Students
}

\author{
Chauhan Ajay* \\ Department of Psychology, Sardar Patel University, India
}

Submission: September 12, 2016; Published: November 22, 2016

*Corresponding author: Chauhan Ajay, Research Scholar, Department of Psychology, Sardar Patel University, Vallabh Vidyanagar, Gujarat, India, Email: psy.ajchauhan@gmail.com

\begin{abstract}
Today Education is most important in our life. Day to day education system some changes. Education begins at birth and continues throughout life. The achievement motivation is conceived as a latent disposition which is manifested in over striving only when the individual perceives performance as instrument to a sense of personal accomplishment. Anxiety is your body's way of telling you that there is something in the environment in need of your attention. It is basically a series of biochemical changes in your brain and body. Present study's main aim an achievement motivation and academic anxiety relation between school going students.
\end{abstract}

Abbreviations: TAT: Thematic Apperception Test; AAA: Appraisal-anxiety Avoidance; AASC: Academic Anxiety Scale for Children

\section{Introduction}

Education is the process of developing the capacities and potentials of the individual so as to prepare that individual to be successful in a specific society or culture. From this perspective, education is serving primarily as an individual development function. Education begins at birth and continues throughout life. It is constant and ongoing. Schooling generally begins somewhere between the ages four and six when children are gathered together for the purposes of specific guidance related to skills and competencies that society deems important. In the past, once the formal primary and secondary schooling was completed the process was finished. However, in today's information age, adults are quite often learning in informal setting throughout their working lives and even into retirement.

\section{Definition motivation}

The term motivation is derived from the word 'Movex' or the 'Matum', which meats la move, motor and motion. It is the move towards set goals; therefore, motivation is a force which energizes the behavior of learners. Motivation has been defined in many ways. Some say it is the stimulation of actions towards a particular objective where previously there was little or no attraction to that objective. Blair, Jones and Simpton believe that motivation is a process in which the learner's internal energies or needs are directed toward various goals and objects in his environment. Good says that motivation is the process of arousing sustaining and regulating activity. Some other important definitions are given below -

Motivation of people depends on the strength of their motives. Motives are defined as needs, wants, drives, or impulses within the individual. Motives are the "whys" of behavior.

i. 'Motivation is to find those approaches that will make the child eager for the kind of learning the school endorses.'Bernard

ii. 'Motivation is the influence of general pattern of activities indicating and directing the behavior of the organism.' -Johnson

iii. "Motivation is the process of arousing, sustaining and regulating activity". -Good

iv. "The term motivation refers to the arousal of tendency to act to produce one or more effects"- Atkinson

v. "Motivation is constant, never ending, fluctuating and complex and that it is almost universal characteristic of particularly every organismic state of affairs."- Maslow

\section{Definition achievement motivation}

A behavior can be considered achievement motivated when it involves "competition with a standard of excellence." 
i. $\quad$ "The achievement motivation is conceived as a latent disposition which is manifested in over striving only when the individual perceives performance as instrument to a sense of personal accomplishment"-Atkinson \& Feather

ii. "Achievement motivation is defined in terms of the way an individual orients himself towards object of conditions that he does not process. If he values those objects and condition and he feels that he ought to process them, he may be regarded as having an Achievement motive." -Irving Sarnoff

\section{How to Develop Achievement Motive:}

a) The teacher should make clear the importance of achievement motive in life by means of telling the stories of great men and their achievements from all walks of life. When the students are convinced in advance to believe that they would or should develop achievement motive, the effort of the teacher will succeed.

b) The teacher should provide a proper environment both inside and outside the class. The teacher's attitude and enthusiasm will create better environment for achievement motive in children.

c) The teacher will succeed in his attempt if he convinces the students that developing a new motive is realistic and reasonable.

d) The teacher should relate the motive with future life of the students and assign independent responsibility to them.

e) The teacher should make clear to the student that the new motive will improve their self-image.

f) The teacher should emphasize upon the fact that new motive is an improvement on prevailing cultural values.

g) The teacher should make students committed to achieving concrete goals in life related to the newly developed motive.

h) The teacher should ask the students to keep the record of their progress towards their goal.

i) Self -study should be emphasized.

j) The teacher should make an effort to develop conducive social climate in the class so that every individual should feel that he belongs to a group.

Measuring achievement motive: McClelland and coworkers believed that our fantasies often reveal motivational basis of our actions. He attempted to make use of the fantasies to explore and measure achievement motivation. Hetried in to collect information from his subject by menus of projective technique's creative production. He is TAT (Thematic Apperception Test) pictures to collect information on the fantasies of the subjects. The assumption underlying TAT pictures is that when we present a picture of another person in a social setting under ambiguous and unstructured circumstances and ask him to tell a story about what is happening in the picture, in doing so he (subject) may often reveal about himself.

McClelland and his associates made qualitative and quantitative studies of TAT stories written by their subjects. The results as reported by them were positive. The technique is reliable and promises development in the field of measuring motivation. The most significant contribution of McClelland and associates is that they advocated that motives develop out of affective arousal. Their theory of motivation is called affective arousal theory [1-3].

Motivation in the Class: In the preceding part of this research, we have briefly surveyed the development of the concept of motivation and its major theories. Now we will deal with the practical aspect of motivation in the classroom teaching-learning situation. Every teacher daily faces a number of behavior problems. For the explanation of these problems, he has to turn to psychology of motivation. This is great problem for teachers, parents and administrators and for those who are interested in the improvement of performance and learning of people for action. Student in the classroom learning require constant motivation from the teacher so that maximum use of their talents may be made for their welfare and also for the welfare and progress of the society. The process of motivation is a highly individualized activity in the sense that causes underlying behavior are always multiple and complex rather than single and simple.

A leaner may be motivated for an action in a particular situation and the other learner may not be motivated in that situation and even the same learner may not be motivated under the same situation on some different occasions. A number of variables operate in the process of motivation which causes variation in the individuals. The socio-economic condition, previous experience, age and social climate in the classroom affect the process of motivation. Psychologists have developed some common techniques which may be used by classroom teachers so motivate children in their work. The teacher should not strictly adhere to one theory of motivation but he should make use of various approaches in his teaching, keeping into consideration the indi $\neg$ vidual differences among the studies. Below are given some of the important techniques of motivation in the classroom teaching-learning situations (Figure 1):

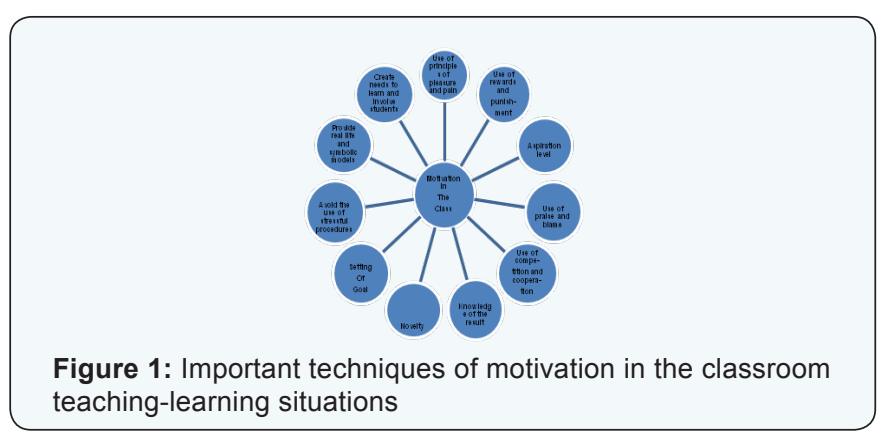


Academic anxiety: Anxiety is your body's way of telling you that there is something in the environment in need of your attention. It is basically a series of biochemical changes in your brain and body, such as an increase in adrenaline (causing your heart to beat faster) and a decrease in dopamine (a brain chemical that helps to block pain). These changes result in a state of heightened attention to the source of the anxiety. High levels of anxiety cause your body to prepare to fight or run away from the perceived threat commonly called the "fight-or-flight response."

\section{Causes academic anxiety}

\section{a. General Academic Anxiety:}

i. Attending group lectures/tutorials where you might have to answer questions or give oral presentations/ participate in group discussions.

ii. Drafting and submitting assignments/reports

\section{b. Examination Activities:}

i. Exam preparation (studying)

ii. Writing the exam

B. Symptoms of academic anxiety

i. Physical symptoms

ii. Intellectual symptoms

iii. Emotional symptoms

\section{Review of the Literature}

Research is made in order to inform people with new knowledge or discovery. However, it is not to be expected that everybody would willingly believe what you are tackling in your whole research. Thus, what researcher can do to make your research more credible will be to support them with other works which have spoken about the same topic that you have for research. This is where literature review comes in. Researcher can even have literature sources in works such as stories, comments, project, speech, article, novel, poem, essay, program, theory, and others [4]. This is why literature review involves scanning the pages of any published literature like books, newspaper, magazine, website, webpage, collection, paper, pamphlet, and the like where researcher may be able to find any reference to the same topic that you are researching on. This time, "literature"" does not exclusively refer to the poetic rendition of words, like that of Shakespeare alone.

There are many reasons why literature review is rendered as a significant part of any research or dissertation. Researcher may ask what makes it as such if it is only supposed to contain tidbits of other related works. Literature review is the part of the research where the researcher will be given the opportunity to strengthen research for will be citing what other reliable authors have said about research topic. This will prove that researcher is not just writing about any random subject but that many others have also poured their thought son the topic. The main objectives of the study are to study the effect of gender, area of residence, type of school and category of the student on the achievement motivation, and academic anxiety. So researcher found many research on this topic and very usefully to in this research. Some researchers are given bellow.

\section{Achievement Motivation}

\section{Habibahelias and atan bin longa (1984)}

Correlation Study of Achievement Motivation and Pupils' Performance in the Standard Five Assessment Examination From Selected Schools in Selangor. The performance of pupils in the Primary Five Assessment Examination was examined in relation to a number of variables namely achievement motivation, socioeconomic status, intelligence, area of residence, school milieu and parental encouragement to assess the correlation between them. The subjects were 90 pupils selected from 40 primary schools in Selangor and represented the Chinese, Malays and Indians. Individual interviews were conducted by the researcher. Subjects were asked to answer questionnaires, the Thematic Apperception Test, and the Raven's Progressive Matrices. The results showed that achievement motivation correlated highly with performance in the stated examination. The other variables which showed significant correlations with performance were socio-economic status, intelligence, school milieu and parental encouragement [5].

\section{Allen Slade L. AND Michael C. Rush (1991)}

Achievement Motivation and the Dynamics of Task Difficulty Choices, Undergraduate students performed a vigilance task in a study of the dynamic theory of achievement motivation. Positively motivated subjects $(n=66)$ and negatively motivated subjects $(n=60)$ did not differ in initial task difficulty choices. Both groups shifted to more difficult tasks over time, but this linear trend interacted with achievement motive group, with positively motivated subjects shifting faster. Quadratic and cubic trends in task difficulty choices were also observed. Periodic interruptions attenuated achievement group differences in average task difficulty choices. Subject gender affected average task difficulty choices, but gender did not interact with theoretically important variables in this study.

\section{Ellekkakumar, B. and Elankathirselvan, N (2001)}

Achievement Motivation of Higher Secondary Students and their Achievement in Physics, the aim of this study.

i. To assess the achievement motivation of higher secondary students in Physics and achievement in Physics:

ii. To find out whether there is any significant difference between mean scores and achievement scores of boys and girls and in Tamil medium and English medium; 
iii. To find out the nature of relationship between the components of achievement motivation and achievement of higher secondary students in Physics.

Descriptive-Normative survey method was employed in the study. The sample was taken 530 students studying in Physics in the second year of higher secondary school, in Cuddalore district in Tamil Nadu, using probability sampling method for the study. Tools were used such as 46 Indian Educational Abstracts Achievement Motivation Inventory (Prayag Mehta, 1969) and Academic Achievement for the study.

i. The mean scores of achievement related motivation was higher for girls than boys.

ii. There was no significant difference between the students studying in Tamil medium and the students studying in English medium.

iii. There was no significant difference in achievement mean scores in Physics between

a. Boys and Girls,

b. A group and B group,

c. Tamil medium and English medium.

iv. The positive correlations were found between the achievement related motivation and achievement marks in Physics in respect of

a. girls,

b. students studying in Tamil medium. This study can be extended in other districts. Nine references were cited in the study.

\section{Vijayakumari (2010)}

Some correlates of academic achievement of secondary school students. This study focuses on the relationship of academic anxiety and achievement motivation with academic achievement. I also try to find out the main and interaction effects of academic anxiety, achievement motivation and sex on academic achievement. This study was conducted on sample of 400 ninth standard students of kerala state. Findings of the study reveal that academic achievement is negatively related to academic anxiety and positively related to achievement motivation [6-10]. The main effects of three variables, academic anxiety, achievement motivation and sex on academic achievement is significant and the interaction effect of academic anxiety and sex as well as achievement motivation and sex are significant on academic achievement.

\section{Academic Anxiety}

\section{Adele Eskeles Gottfried (1981)}

Relationships between academic intrinsic motivation and anxiety in children and young adolescents, in this study to test the hypothesis that academic intrinsic motivation and anxiety are negatively related when both are differentiated into academic subject areas, two self-report inventories measuring academic intrinsic motivation and anxiety were administered to fourth and seventh graders. Each inventory was differentiated into the subject areas of reading, math, social studies, and science to determine whether the relationship between academic intrinsic motivation and anxiety would vary according to subject area. The results supported the hypothesis and showed that the relationship is differentiated according to subject area. Fourth and seventh graders differed in the pattern of relationships. For seventh graders, negative correlations between academic intrinsic motivation and anxiety occurred only within corresponding subject areas, while for fourth graders the negative correlations occurred both within corresponding and between no corresponding subject areas. Implications for assessment and school intervention are advanced.

\section{Wigfield Allan and Meece Judith L. (1988)}

Math Anxiety in Elementary and Secondary School Students, in this study assessed math anxiety in $6^{\text {th }}$ - through $12^{\text {th }}$-grade children $(\mathrm{N}=564)$ as part of a comprehensive longitudinal investigation of children's beliefs, attitudes, and values concerning mathematics. Confirmatory factor analyses provided evidence for two components of math anxiety, a negative affective reactions component and a cognitive component. The affective component of math anxiety related more strongly and negatively than did the worry component to children's ability perceptions, performance perceptions, and math performance. The worry component related more strongly and positively than did the affective component to the importance that children attach to math and their reported actual effort in math. Girls reported stronger negative affective reactions to math than did boys. Ninth-grade students reported experiencing the most worry about math and sixth graders the least.

\section{Norman Milgram and Yosef Toubiana (1999)}

Academic anxiety, academic procrastination, and parental involvement in students and their parents, the study investigated the relationship between academic anxiety and procrastination in children and parents, and parents' direct involvement in their children's schoolwork design. Children reported their current anxiety and procrastination and parents reported their anxiety and procrastination when they were children (a measure of indirect influence on their children's schoolwork habits), and on their current involvement in their children's schoolwork (a measure of direct influence).

i. Methods: Self-report measures were administered to 354 Israeli adolescents (ages 13, 14, and 16) and their parents.

ii. Results: Students were less anxious about homework than the other academic assignments. Older adolescents were less anxious about their schoolwork overall and procrastinated more than younger on homework. Parents 
of late adolescents were less involved in their children's schoolwork than parents of younger adolescents. Parents participated equally in school-related interactions that demanded high investment of time and effort, but mothers engaged more than fathers in low investment activities. These direct and indirect parental influences on their children's procrastination were of low magnitude overall, but appeared relatively stronger for mothers. The more students were anxious about preparing for examinations and writing papers, the more they procrastinated on these assignments, confirming the appraisal-anxiety avoidance (AAA) model. The inverse relationship of anxiety and procrastination with regard to homework led to our making a post hoc distinction between task-centered and consequence-centered anxiety.

\section{Yagnik L. R and Gunthey R. K. (2001)}

Academic Anxiety among Rural and Urban Children and Its Implications, Presently our culture is paying more attention to child's academic achievement. This tension is perceived by child as an academic pressure. The multi-dimensional growth of the child's brain is restricted due to this pressure only few of the dimensions are properly canalized and rests of the dimensions are left intact. In the present investigation an attempt is made to compare the academic anxiety level of rural and urban children. Three groups of Government school (Urban), Private school (Urban) and Government school (Rural) were taken. 65 male students of class V and VI standard were taken in each group. Academic Anxiety Scale (Singh and Gupta, 1971) and Anxiety Scale (Sinha, 1974) were used to measure anxiety level of child and parents respectively Significant difference is reported among all the groups, except Government and private schools of urban setup. Similarly parents of three groups differ significantly from each other.

\section{Method and Design}

The present study was undertaken to know the achievement motivation, and academic anxiety problems of standard - $9^{\text {th }}$ to $12^{\text {th }}$ students studying in secondary - higher secondary school of the Bhavnagar district.

\section{Statement of the Problem}

"An Achievement Motivation and Academic Anxiety of School Going Students"

\section{Objectives of the Study}

The following main objectives were formulated for the present study.

a. To study the effect of sex (boy-girl) on an achievement motivation.

b. To find out whether there is any significant difference in achievement motivation of urban and rural students.

c. To check out whether there is any significant difference in achievement motivation of private and government school's students.

d. To examine the effects of achievement motivation reserved and non - reserved students.

e. To study the effect of sex (boy-girl) on an academic anxiety.

f. To find out whether there is any significant difference in academic anxiety of urban and rural students.

g. To check out whether there is any significant difference in academic anxiety of private and government school's students.

h. To examine the effects of academic anxiety reserved and non - reserved students.

i. To check out the relationship between achievement motivation and academic anxiety in boys-girls students.

j. To check out the relationship between achievement motivation and academic anxiety in urban and rural students.

k. To check out the relationship between achievement motivation and academic anxiety in private and government school's students.

l. To check out the relationship between achievement motivation and academic anxiety in reserved and non reserved students.

\section{Hypothesis}

The following research null hypotheses were tested in the present study.

a. There is no significant difference in achievement motivation between male and female students.

b. There is no significant difference in the achievement motivation between urban and rural students.

c. There is no significant difference in the achievement motivation between private and government school's students.

d. There is no significant difference in the achievement motivation between reserved and non - reserved students.

e. There is no significant correlation between the matter academic anxiety and achievement motivation in boys.

f. There is no significant correlation between the matter academic anxiety and achievement motivation in girls.

g. There is no significant correlation between the academic anxiety and achievement motivation of urban students.

h. There is no significant correlation between the academic anxiety and achievement motivation of rural students. 


\section{Psychology and Behavioral Science International Journal}

i. There is no significant correlation between the academic anxiety and achievement motivation of private school's students.

j. There is no significant correlation between the academic anxiety and achievement motivation of government school's students.

k. There is no significant correlation between the academic anxiety and achievement motivation of reserved students.

l. There is no significant correlation between the academic anxiety and achievement motivation of non reserved students.

\section{Variables}

In present research following variables was studied and the nature of variables under study is given in the following table (Table 1).

Table 1: Nature and level of selected variables.

\begin{tabular}{|c|c|c|c|c|}
\hline NO. & $\begin{array}{l}\text { Name of } \\
\text { Variable }\end{array}$ & $\begin{array}{l}\text { Nature of } \\
\text { variable }\end{array}$ & $\begin{array}{c}\text { Number of } \\
\text { Level }\end{array}$ & $\begin{array}{c}\text { Name of } \\
\text { Level }\end{array}$ \\
\hline 1. & Gender & $\begin{array}{c}\text { Independent } \\
\text { Variable }\end{array}$ & 2 & $\begin{array}{l}\text { (1) Boy } \\
\text { (2) Girl }\end{array}$ \\
\hline 2. & $\begin{array}{l}\text { Area of } \\
\text { residence }\end{array}$ & $\begin{array}{c}\text { Independent } \\
\text { Variable }\end{array}$ & 2 & $\begin{array}{l}\text { (1) Urban } \\
\text { (2) Rural }\end{array}$ \\
\hline 3. & $\begin{array}{l}\text { Type of } \\
\text { school }\end{array}$ & $\begin{array}{c}\text { Independent } \\
\text { Variable }\end{array}$ & 2 & $\begin{array}{l}\text { (1) Granted } \\
\text { (2) Non } \\
\text { Granted }\end{array}$ \\
\hline 4. & Category & $\begin{array}{c}\text { Independent } \\
\text { Variable }\end{array}$ & 2 & $\begin{array}{c}\text { (1) Reserved } \\
\text { (2) Non } \\
\text { Reserved }\end{array}$ \\
\hline 5. & $\begin{array}{l}\text { Achievement } \\
\text { motivation }\end{array}$ & $\begin{array}{l}\text { Dependent } \\
\text { Variable }\end{array}$ & 1 & $\begin{array}{c}\text { Level of } \\
\text { Achievement } \\
\text { Motivation }\end{array}$ \\
\hline 6. & $\begin{array}{l}\text { Academic } \\
\text { anxiety }\end{array}$ & $\begin{array}{l}\text { Dependent } \\
\text { Variable }\end{array}$ & 1 & $\begin{array}{l}\text { Level of } \\
\text { Academic } \\
\text { Anxiety }\end{array}$ \\
\hline
\end{tabular}

\section{Sample}

According to the objectives of this study, the population of this research is students of all secondary and higher secondary school of the Bhavnagar district, where standard - $9^{\text {th }}$ to $12^{\text {th }}$ has been taught. In this research samples was selected randomly from all secondary schools in the Bhavnagar district. Researcher was selected 240 boys and 240 girls' students from different school. So there were total 480 samples selected in this research (Table 2).
Table 2: Various Level wise Distribution of the sample.

\begin{tabular}{|l|l|l|l|l|l|l|l|l|l|}
\hline Variable & A1 & & & & A2 & & & & Total \\
\hline & B1 & & B2 & & B1 & & B2 & & \\
\hline & C1 & C2 & C1 & C2 & C1 & C2 & C1 & C2 & \\
\hline D1 & 30 & 30 & 30 & 30 & 30 & 30 & 30 & 30 & 240 \\
\hline D2 & 30 & 30 & 30 & 30 & 30 & 30 & 30 & 30 & 240 \\
\hline Total & $\mathbf{6 0}$ & $\mathbf{6 0}$ & $\mathbf{6 0}$ & $\mathbf{6 0}$ & $\mathbf{6 0}$ & $\mathbf{6 0}$ & $\mathbf{6 0}$ & $\mathbf{6 0}$ & $\mathbf{4 8 0}$ \\
\hline
\end{tabular}

A1: Boys B1: Urban

C1: Private School D1: Reserved

A2: Girls B2: Rural C2: Goverment School

D2: Non -Reserved

\section{Tools}

Following tools were used to collect the data from students.

a. Achievement motivation inventory- Ashvin Jansari: In this study Investigator was used Achievement motivation inventory by AshvinJansari for testing of the student's Achievement motivation. It inventory published by Bhatri Manomapan Centre, Ahmedabad, Gujarat, India. The inventory can be administered to individuals as well as in groups of 30 to 40 . It has a 25 items. Every item has six options. In this inventory the overall scores give a measure of Achievement motivation.

i. Reliability: The reliability of the AMI test was computed through two methods, that is, test-retest method and the split method. In order to compute the test-retest reliability, the test was administered twice on a sample of 120 pupils with 30 days gap. Subsequently, Pearson $r$ was computed between the two sets of scores. The obtained Coefficient of correlation was 0.6301 . For the split half reliability of the test, it was administered on a fresh sample of 120 students. The resulting correlation coefficient was 0.7245 .

ii. Validity: The inventory, besides having high face validity, has the other validity coefficients which are given below (Table 3):

b. Academic anxiety scale for children - A. K. Singh and A. San Gupta: In this study investigator was used academic anxiety scale for children by A. K. Singh and A. San Gupta for testing of the student's academic anxiety. It scale published by national psychological corporation, Agra, India. This is a two point scale with 25 items. Every item has two -point as like 'yes', and 'no'. In this inventory the overall scores give a measure of Academic anxiety.

i. Reliability: The reliability of the AASC test was computed through two methods, that is, test-retest method and the split method. In order to compute the test-retest reliability, the test was administered twice on a sample of 100 pupils with 14 days gap. Subsequently, Pearson $r$ was computed between the two sets of scores. The obtained 
Pearson $r$ was 0.60 which was significant beyond 0.01 levels. For the split half reliability of the test, it was administered on a fresh sample of one hundred. Subsequently, the test was spited by the odd-even method. The resulting oddeven correlation coefficient was 0.433 which, after being corrected for full length, became 0.65 .

Table 3: Validity of Achievement motivation inventory.

\begin{tabular}{|c|c|c|c|}
\hline Sr. no & Name of tests & $\mathbf{N}$ & Validity coefficients \\
\hline 1. & TAT AND AMS & 50 & 0.5411 \\
\hline 2. & AMT AND AMS & 100 & 0.5683 \\
\hline
\end{tabular}

ii. Validity: (Table 4) The present test has been validated against the sinha-anxiety test. Neuroticism scale of MPI and CAAT. Former two tests are the measures of general anxiety and the latter intends to measure academic anxiety among school children. Table 3 presents the validity coefficients of AASC against these different measures. On the basis of the obtained correlation coefficients it can be said that academic anxiety scale for children AASC is a valid test.

Table 4: Validity.

\begin{tabular}{|c|c|c|c|c|}
\hline Test & Criterion & $\begin{array}{c}\text { correlation } \\
\text { Coefficient }\end{array}$ & N & p \\
\hline Academic & Neuroticism scale & $0.31^{*}$ & 100 & $<0.01$ \\
\hline $\begin{array}{c}\text { Anxiety } \\
\text { scale }\end{array}$ & $\begin{array}{c}\text { Sinha-anxiety } \\
\text { scale }\end{array}$ & $0.41^{*}$ & 100 & $<0.01$ \\
\hline AASC & CAAT & $0.57^{*}$ & 100 & $<0.01$ \\
\hline
\end{tabular}

\section{Research Method}

This research was focus on achievement motivation, and academic anxiety of school going students. So researcher was in the beginning take the list of secondary school of the Bhavnagar district. Then keeping in mind the objectives of this research, schools were selected from this list by random method. After this processes students was selected as a sample from selected school. Investigator was got permission of proper time and will take visit of the school and give some instruction and tool for data collection. The inventory was administered individually on the groups of students. The students were asked to read instructions carefully and give their responses genuinely on all the items of score collecting tool. Totally 480 students data added in last sample. The analysis of the data was prepared by data sheet. The analysis of row data was prepared by necessary and proper statistical method.

\section{Statistical techniques}

In this research the obtained data was tabulated and analyzed. ' $t$ ' test was employed study the significant difference between the means of scores of gender boys and girls, area of residence urban and rural, granted and non granted schools, reserved and non reserved category on achievement motivation, and academic anxiety. Pearson's rank correlation method was employed to examine the relationship between achievement motivation, and academic anxiety.

\section{Result and Discussion}

The purpose of the current study is to examine any significant difference an achievement motivation, and academic anxiety of school going students. In this research the obtained data was tabulated and analyzed. ' $t$ ' test was employed study the significant difference between the means of scores of gender boys and girls, area of residence urban and rural, granted and non granted schools, reserved and non reserved category on achievement motivation, and academic anxiety. Pearson's rank correlation method was employed to examine the relationship between achievement motivation, and academic anxiety.

\section{' $t$ ' test related result}

The $t$ test of significance was used to determine the significance of difference between mean scores of the total achievement motivation in respect of school going students. Results of such an analysis are presented in the following tables and figure.

Table 5: Mean, SD, SED and't' value of achievement motivation scores of male and female students.

\begin{tabular}{|c|c|c|c|c|c|c|}
\hline GROUP & \multirow{2}{*}{ N } & MEAN & SD & SED & \multicolumn{2}{|c|}{ 't' Value } \\
\cline { 1 - 4 } & & & & & Tabulated & Calculated \\
\hline Male & 240 & 39.73 & 5.91 & 0.55 & 2.58 & 3.89 \\
\hline Female & 240 & 37.60 & 6.09 & & & \\
\hline
\end{tabular}

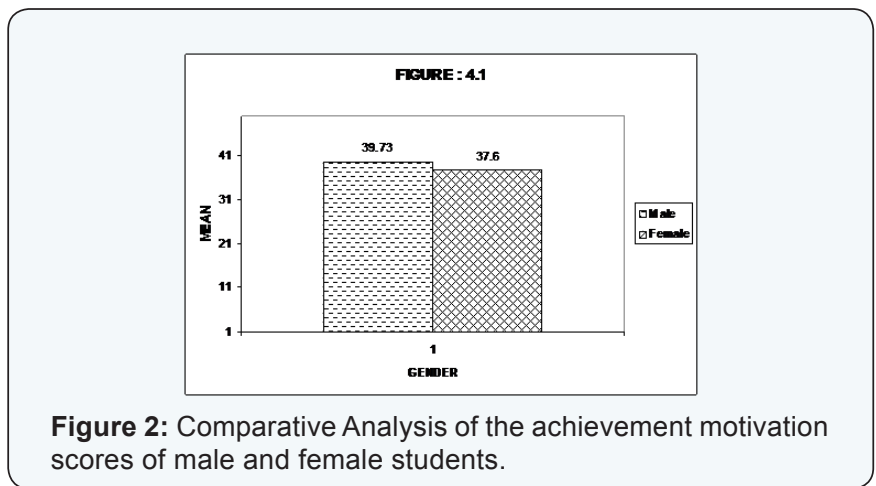

HO 1: There is no significant difference in achievement motivation between male and female students. (Table 5) \& (Figure 2) The graph shows the achievement motivation scores of male and female students. The achievement motivation score of male students found to be higher as compared to the female students. The t-test was applied to see the significance of difference between the mean scores of the male and female 


\section{Psychology and Behavioral Science International Journal}

students. It was found that the scores of male students on Achievement motivation inventory $(M=39.73, S D=5.91)$ was significantly higher than female students $(M=37.60, S D=6.09)$. The calculated value of $\mathrm{t}=3.89$ was found greater than the tabulated value $t=2.58$ at 0.01 level of significance.

Researcher can also associate this analysis with the M. Chaturvedi (2009) entitled "School Environment, Achievement Motivation and Academic Achievement". One of the most important conclusions of that study the scores on achievement motivation as well as academic achievement differed significantly in case of gender grades. The similar result is found in this study.

Table 6: Mean, SD, SED and't' value of achievement motivation scores of urban and rural students.

\begin{tabular}{|c|c|c|c|c|c|c|}
\hline \multirow{2}{*}{ GROUP } & \multirow{2}{*}{$\mathbf{N}$} & \multirow{2}{*}{ MEAN } & \multirow{2}{*}{ SD } & \multirow{2}{*}{ SED } & \multicolumn{2}{|c|}{ 't' Value } \\
\cline { 1 - 3 } & & & & & Tabulated & Calculated \\
\hline Urban & 240 & 40.56 & 4.95 & & & \\
Rural & 240 & 36.77 & 6.52 & & 2.58 & 5.28 \\
\hline
\end{tabular}

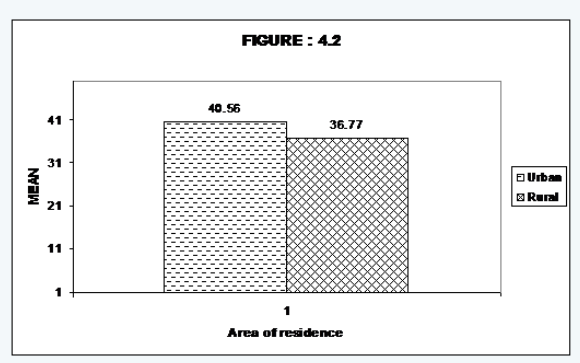

Figure 3: Comparative Analysis of the achievement motivation scores of urban and rural students.

HO 2: There is no significant difference in the achievement motivation between urban and rural students. (Table 6) \& (Figure 3) The graph shows the achievement motivation scores of urban and rural students. The achievement motivation score of urban students found to be higher as compared to the rural students. The t-test was applied to see the significance of difference between the mean scores of the urban and rural students. It was found that the scores of urban students on Achievement motivation inventory $(M=40.56, S D=4.95)$ was significantly higher than rural students $(\mathrm{M}=36.77, \mathrm{SD}=6.52)$. The calculated value of $\mathrm{t}=5.28$ was found greater than the tabulated value $\mathrm{t}=$ 2.58 at 0.01 level of significance.

Table 7: Mean, SD, SED and't' value of achievement motivation scores of private and government school's students.

\begin{tabular}{|l|c|c|c|c|c|c|}
\hline \multirow{2}{*}{ GROUP } & \multirow{2}{*}{$\mathbf{N}$} & \multirow{2}{*}{ MEAN } & SD & SED & Tabulated & Calculated \\
\cline { 5 - 7 } & & & & & & \multicolumn{2}{|c|}{ 't' Value } \\
\hline Private & 240 & 39.89 & 6.44 & 0.51 & 2.58 & 4.87 \\
\hline Private & 240 & 39.89 & 6.44 & 0.51 & 2.58 & 4.87 \\
\hline
\end{tabular}

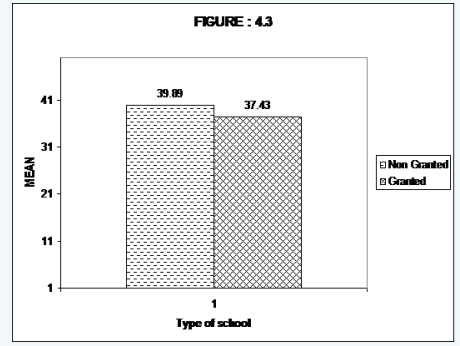

Figure 4: Comparative Analysis of the achievement motivation scores of private and government school's students.

HO 3: There is no significant difference in the achievement motivation between private and government school's students. (Table 7) \& (Figure 4) The graph shows the achievement motivation scores of private and government school's students. The achievement motivation score of private school's students found to be higher as compared to the government school's students. The t-test was applied to see the significance of difference between the mean scores of the private and government school's students. It was found that the scores of private school's students on Achievement motivation inventory $(\mathrm{M}=39.89, \mathrm{SD}=6.44)$ was significantly higher than government school's students ( $\mathrm{M}=37.43, \mathrm{SD}=4.45)$. The calculated value of $\mathrm{t}=4.87$ was found greater than the tabulated value $\mathrm{t}=2.58$ at 0.01 level of significance.

Table 8: Mean, SD, SED and't' value of achievement motivation scores of reserved and non reserved students.

\begin{tabular}{|c|c|c|c|c|c|c|}
\hline GROUP & N & MEAN & SD & SED & \multicolumn{2}{|c|}{ 't' Value } \\
\hline Reserved & 240 & 40.73 & 5.51 & & Tabulated & Calculated \\
\cline { 1 - 4 } $\begin{array}{c}\text { Non } \\
\text { reserved }\end{array}$ & 240 & 36.60 & 5.95 & 0.53 & 2.58 & 7.89 \\
\hline
\end{tabular}

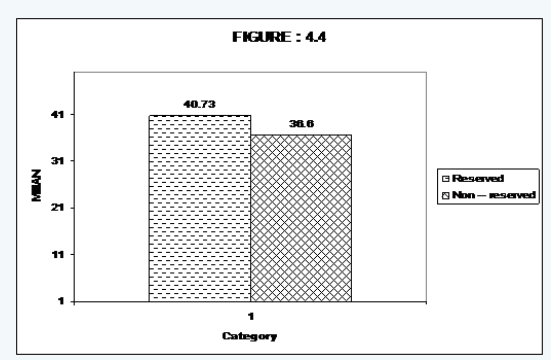

Figure 5: Comparative Analysis of the achievement motivation scores of reserved and non reserved students.

HO 4: There is no significant difference in the achievement motivation between reserved and non reserved students. (Table 8) \& (Figure 5) The graph shows the achievement motivation scores of reserved and non - reserved students. The achievement motivation score of reserved students found to be higher as compared to the non reserved students. The t-test was applied to see the significance of difference between the mean scores 


\section{Psychology and Behavioral Science International Journal}

of the reserved and non reserved student. It was found that the scores of private school's students on Achievement motivation inventory ( $M=40.73, S D=5.11)$ was significantly higher than government school's students $(M=36.60, \mathrm{SD}=5.95)$. The calculated value of $\mathrm{t}=7.89$ was found greater than the tabulated value $t=2.58$ at 0.01 level of significance.

\section{Academic anxiety}

HO 5: There is no significant difference in the academic anxiety between male and female students. (Table 9) \& (Figure 6) The graph shows the academic anxiety scores of male and female students. The academic anxiety score of male students found to be higher as compared to the female students. The t-test was applied to see the not significance of difference between the mean scores of the male and female students. It was found that the scores of male students on Academic anxiety scale for children ( $M=10.20, S D=5.08)$ was not significantly higher than female students $(M=9.78, S D=5.50)$. The calculated value of $t$ $=0.87$ was found lower than the tabulated value $\mathrm{t}=1.96$ at 0.05 level of significance.

Table 9: Mean, SD, SED and't' value of academic anxiety scores of male and female students.

\begin{tabular}{|c|c|c|c|c|c|c|}
\hline \multirow{2}{*}{ GROUP } & \multirow{2}{*}{$\mathbf{N}$} & MEAN & SD & \multirow{2}{*}{ SED } & \multicolumn{2}{|c|}{ 't' Value } \\
\cline { 6 - 7 } & & & & & Tabulated & Calculated \\
\hline Male & 240 & 10.20 & 5.08 & & & \\
\hline Female & 240 & 9.78 & 5.50 & & & \\
\hline
\end{tabular}

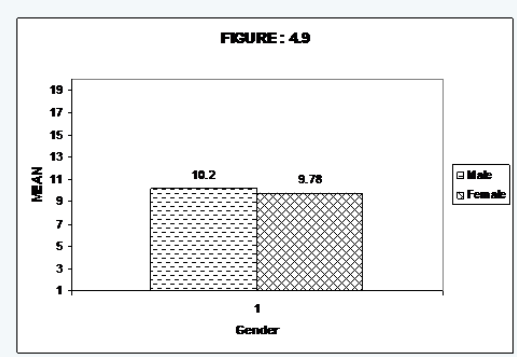

Figure 6: Comparative Analysis of the academic anxiety scores of male and female students.

Table 10: Mean, SD, SED and't' value of academic anxiety scores of urban and rural students.

\begin{tabular}{|c|c|c|c|c|c|c|}
\hline \multirow{2}{*}{ GROUP } & \multirow{2}{*}{$\mathbf{N}$} & \multirow{2}{*}{ MEAN } & \multirow{2}{*}{ SD } & \multirow{2}{*}{ SED } & \multicolumn{2}{|c|}{ 't' VALUE } \\
\hline & & & & & Tabulated & Calculated \\
\hline Urban & 240 & 10.50 & 5.06 & & & \\
\hline Rural & 240 & 9.48 & 5.48 & & & \\
\hline
\end{tabular}

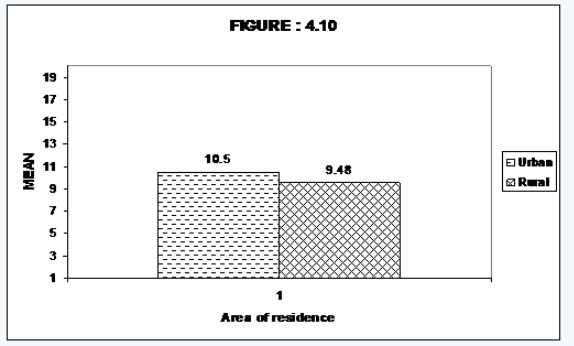

Figure 7: Comparative Analysis of the academic anxiety scores of urban and rural students.

HO 6: There is no significant difference in the academic anxiety between urban and rural students. (Table 10) \& (Figure 7) The graph shows the academic anxiety scores of urban and rural students. The academic anxiety score of urban students found to be higher as compared to the rural students. The t-test was applied to see the significance of difference between the mean scores of the urban and rural students. It was found that the scores of urban students on Academic anxiety scale for children ( $M=10.50, S D=5.06)$ was not significantly higher than rural students $(M=9.48, S D=5.48)$. The calculated value of $t=$ 2.12 was found greater than the tabulated value $t=1.96$ at 0.05 level of significance.

Table 11: Mean, SD, SED and't' value of academic anxiety scores of private and government school's students.

\begin{tabular}{|c|c|c|c|c|c|c|}
\hline \multirow[b]{2}{*}{ GROUP } & \multirow[b]{2}{*}{$\mathbf{N}$} & \multirow[b]{2}{*}{ MEAN } & \multirow[b]{2}{*}{ SD } & \multirow{2}{*}{ SED } & \multicolumn{2}{|c|}{ 't' VALUE } \\
\hline & & & & & Tabulated & Calculated \\
\hline $\begin{array}{c}\text { Non } \\
\text { Granted }\end{array}$ & 240 & 10.13 & 5.35 & \multirow{2}{*}{0.48} & \multirow{2}{*}{1.96} & \multirow{2}{*}{0.60} \\
\hline Granted & 240 & 9.84 & 5.25 & & & \\
\hline
\end{tabular}

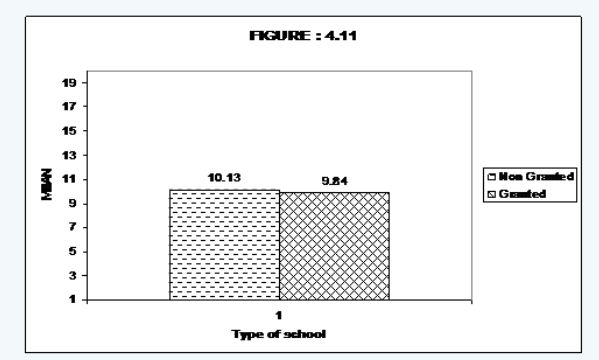

Figure 8: Comparative Analysis of the academic anxiety scores of private and government school's students.

HO 7: There is no significant difference in the academic anxiety between private and government school's students. (Table 11) \& (Figure 8) The graph shows the academic anxiety scores of non granted school's students and non granted school's students. The academic anxiety score of non granted school's students found to be higher as compared to the granted school's 
students. The t-test was applied to see the not significance of difference between the mean scores of the private and government school's students. It was found that the scores of non granted school's students on Academic anxiety scale for children ( $M=10.13, \mathrm{SD}=5.35)$ was not significantly higher than granted school's students $(\mathrm{M}=9.84, \mathrm{SD}=5.25)$. The calculated value of $\mathrm{t}=0.60$ was found lower than the tabulated value $\mathrm{t}=$ 1.96 at 0.05 level of significance.

Table 12: Mean, SD, SED and't' value of academic anxiety scores of reserved and non -reserved students.

\begin{tabular}{|c|c|c|c|c|c|c|}
\hline \multirow[b]{2}{*}{ GROUP } & \multirow[b]{2}{*}{$\mathrm{N}$} & \multirow[b]{2}{*}{ MEAN } & \multirow[b]{2}{*}{ SD } & \multirow[b]{2}{*}{ SED } & \multicolumn{2}{|c|}{ 't' VALUE } \\
\hline & & & & & Tabulated & Calculated \\
\hline Reserved & 240 & 10.71 & 5.10 & 0.48 & \multirow{2}{*}{1.96} & \multirow{2}{*}{1.88} \\
\hline $\begin{array}{c}\text { Non } \\
\text { reserved }\end{array}$ & 240 & 9.80 & 5.49 & & & \\
\hline
\end{tabular}

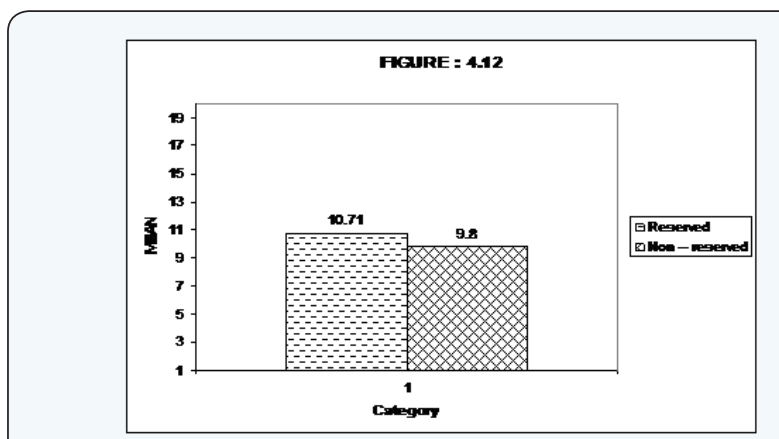

Figure 9: Comparative Analysis of the academic anxiety scores of reserved and non reserved students.

HO 8: There is no significant difference in the academic anxiety between reserved and non - reserved students. (Table 12) \& (Figure 9) The graph shows the academic anxiety scores of reserved and non - reserved students. The academic anxiety score of reserved students found to be higher as compared to the non - reserved students. The t-test was applied to see the no significance of difference between the mean scores of the reserved students and non reserved students. It was found that the scores of reserved students on Academic anxiety scale for children $(M=10.71, S D=5.10)$ was not significantly higher than non - reserved students $(M=9.80, S D=5.49)$. The calculated value of $\mathrm{t}=1.88$ was found lower than the tabulated value $\mathrm{t}=$ 1.96 at 0.05 evel of significance.

\section{Correlation related result}

The spearman's rank order was used to determine the Correlation between scores of the total achievement motivation, study habits and academic anxiety in respect of school going students. Results of such an analysis are presented in the following tables.

\section{Correlation between academic anxiety and achievement motivation}

Table 13: Correlation between the matter academic anxiety and achievement motivation in boys.

\begin{tabular}{|c|c|c|c|}
\hline $\begin{array}{c}\text { Name of } \\
\text { Variable }\end{array}$ & $\mathbf{N}$ & $\mathbf{r}$ & Tabulated \\
\hline $\begin{array}{c}\text { Academic } \\
\text { Anxiety }\end{array}$ & 120 & & 0.112 \\
\cline { 1 - 2 } $\begin{array}{c}\text { Achievement } \\
\text { Motivation }\end{array}$ & 120 & & $0.01=0.25$ \\
\hline
\end{tabular}

a) HO 9: There is no significant correlation between the matter academic anxiety and achievement motivation in boys. Form (Table 13) it can be seen that he obtained "r" value of 0.112 is lower than the table value of 0.19 at 0.05 levels; hence is concluded that there is a no significant relationship between the academic anxiety and achievement motivation in boys. Therefore the null hypothesis is accepted.

HO 10: There is no significant correlation between the matter academic anxiety and achievement motivation in girls. Form (Table 14) it can be seen that he obtained " $r$ " value of 0.018 is lower than the table value of 0.19 at 0.05 levels; hence is concluded that there is a no significant relationship between the academic anxiety and achievement motivation in girls. Therefore the null hypothesis is accepted.

Table 14: Correlation between the matter academic anxiety and achievement motivation in girls.

\begin{tabular}{|c|c|c|c|}
\hline $\begin{array}{c}\text { Name of } \\
\text { Variable }\end{array}$ & $\mathbf{N}$ & $\mathbf{r}$ & Tabulated \\
\hline $\begin{array}{c}\text { Academic } \\
\text { Anxiety }\end{array}$ & 120 & \multirow{2}{*}{0.018} & $0.05=0.19$ \\
\cline { 1 - 2 } $\begin{array}{c}\text { Achievement } \\
\text { Motivation }\end{array}$ & 120 & & $0.01=0.25$ \\
\hline
\end{tabular}

HO 11: There is no significant correlation between the academic anxiety and achievement motivation of urban students. Form (Table 15) it can be seen that he obtained " $r$ " value of 0.43 is 1 more than the table value of 0.19 at 0.05 levels; hence is concluded that there is a significant relationship between the academic anxiety and achievement motivation in urban students. Therefore the null hypothesis is rejected and the other alternate hypothesis is formulated. There is a significant correlation between the academic anxiety and achievement motivation of urban students.

Table 15: Correlation between the academic anxiety and achievement motivation of urban students.

\begin{tabular}{|c|c|c|c|}
\hline $\begin{array}{c}\text { Name of } \\
\text { Variable }\end{array}$ & $\mathbf{N}$ & $\mathbf{r}$ & Tabulated \\
\hline $\begin{array}{c}\text { Academic } \\
\text { Anxiety }\end{array}$ & 120 & & $0.05=0.19$ \\
\hline $\begin{array}{c}\text { Achievement } \\
\text { Motivation }\end{array}$ & 120 & 0.43 & $0.01=0.25$ \\
\hline
\end{tabular}


HO 12: There is no significant correlation between the academic anxiety and achievement motivation of rural students. Form Table 16 it can be seen that he obtained "r" value of 0.04 is lower than the table value of 0.19 at 0.05 levels; hence is concluded that there is a no significant relationship between the academic anxiety and achievement motivation in rural students. Therefore the null hypothesis is accepted.

HO 13: There is no significant correlation between the academic anxiety and achievement motivation of private school's students. Form Table 17 it can be seen that he obtained "r" value of 0.05 is lower than the table value of 0.19 at 0.05 levels; hence is concluded that there is a no significant relationship between the academic anxiety and achievement motivation in private school's students. Therefore the null hypothesis is accepted.

HO 14: There is no significant correlation between the academic anxiety and achievement motivation of government school's students. Form Table 18 it can be seen that he obtained "r" value of 0.10 is lower than the table value of 0.19 at 0.05 levels; hence is concluded that there is a no significant relationship between the academic anxiety and achievement motivation in government school's students. Therefore the null hypothesis is accepted.

HO 15: There is no significant correlation between the academic anxiety and achievement motivation of reserved students. Form Table 19 it can be seen that he obtained "r" value of 0.02 is lower than the table value of 0.19 at 0.05 levels; hence is concluded that there is a no significant relationship between the academic anxiety and achievement motivation in reserved students. Therefore the null hypothesis is accepted.

\section{Findings of the research}

The major findings of the research are as follows

a. There is a significant difference in achievement motivation between male and female students. The achievement motivation score of male students found to be higher as compared to the female students.

b. There is a significant difference in the achievement motivation between urban and rural students. The achievement motivation score of urban students found to be higher as compared to the rural students.

c. There is a significant difference in the achievement motivation between private and government school's students. The achievement motivation score of private school's students found to be higher as compared to the government school's students.

d. There is a significant difference in the achievement motivation between reserved and non reserved students. The achievement motivation score of reserved students found to be higher as compared to the non reserved students. e. There is no significant difference in the academic anxiety between male and female students

f. There is a significant difference in the academic anxiety between urban and rural students. The academic anxiety score of urban students found to be higher as compared to the rural students.

g. There is no significant difference in the academic anxiety between private and government school's students.

h. There is no significant difference in the academic anxiety between reserved and non reserved students.

i. There is no significant correlation between the matter academic anxiety and achievement motivation in boys.

j. There is no significant correlation between the matter academic anxiety and achievement motivation in girls.

k. There is a significant correlation between the academic anxiety and achievement motivation of urban students.

l. There is no significant correlation between the academic anxiety and achievement motivation of rural students.

m. There is no significant correlation between the academic anxiety and achievement motivation of private school's students.

n. There is no significant correlation between the academic anxiety and achievement motivation of government school's students.

o. There is no significant correlation between the academic anxiety and achievement motivation of reserved students.

\section{Limitations of the Study}

The main limitations of the study are as follows

a. In this research only 480 students are included.

b. In this research the tools which we used had also some limitations that limitations are also implies to this research.

c. In this study researcher used' $t$ ' test and correlation method but if LSD test is used than it gives more useful results.

d. In this study the information about the students which researcher got in Bhavnagar district, the results from this information is limited for Bhavnagar district only.

\section{Suggestions for Further Study}

a. Problems and personality of the students can be studied.

b. Academic anxiety of Students of the joint family and separate family can be studied. 
c. The I.Q. of students can be studied.

d. The education level of parents and problems of students can be comparatively studied.

e. Academic Anxiety of Urban and Rural Adolescent Girls in Relation to their Socio-Economic Status can be researched.

f. Mathematics Anxiety, Mathematics Performance and Overall Academic Performance in High School Students can be comparatively studied.

\section{Acknowledgement}

The author appreciates all those who participated in the study and helped to facilitate the research process.

\section{References}

1. Adedeji Tella (2007) The Impact of Motivation on Student's Academic Achievement and Learning Outcomes in Mathematics among Secondary School Students in Nigeria. Eurasia Journal of Mathematics, Science and Technology Education 3(2): 149-156.

2. Alam, M.M (2001) Academic Achievement in Relation to Socioeconomic Status, Anxiety Level and Achievement Motivation: A Comparative Study of Muslim and non-Muslim School Children of Uttar Pradesh, Ph.D., Education. Aligarh Muslim University.
3. Aparnath A (2014) A Study of Academic Anxiety of Secondary School Students With Relation To Their Gender and Religion, The International Journal of Indian Psychology, Volume 1, Issue 4, No.2, ISSN 2348-5396 (e), ISSN: 2349-3429; p.53.

4. Atkinson JW, Feather NT (Ed) (1966) A theory of Achievement Motivation, wily, New York, USA.

5. Cara L. Garcia (2007) Dialectic Dialogue for Academic Anxieties in the Dissertation Process, Ph.D. in Education, Pepperdine University.

6. Chhanasiya B, Jogsan Y (2015) Neuroticism and Academic Achievement Motivation in Adolescent, The International Journal of Indian Psychology, Volume 2, Issue 4,ISSN 2348-5396 (e), ISSN: 2349 3429 (p), DIP: B00322V2I42015.

7. Jain Madhu, Jain aishree (2007) Academic Anxiety among Adolescents: Role of Coaching and Parental Encouragement, National Academy of Psychology, India: Vol. 52, No. 2, 146-148.

8. K Suresh (2016) A Study on Anxiety Level and Academic Achievement of XI Standard Students of Thanjavur District, International Journal of Indian Psychology: Volume 3, Issue 4, No. 57.

9. SahukarGautam (2011) Academic Anxiety of Urban and Rural Adolescent Girls in Relation to their Socio-Economic Status, International Referred Research Journal: October, VoL.III, ISSUE-33.

10. Yagnik L. R, Gunthey R. K (2001) Academic Anxiety among Rural and Urban Children and its Implications, national seminar on psychology in India: past, present and future, 12th Annual Conference of NAOP. 